\title{
Gamonalismo y redes de poder local en el nordeste Antioqueño, (Colombia, 1930-1953) ${ }^{1}$
}

\section{Resumen}

El gamonalismo es atingente al mundo andino, en Ecuador el fenómeno se asocia a una forma de poder político local, que es caracterizado como despótico, su sustento son las sociedades rurales en las que hay subordinación campesina y predominio de la gran propiedad (Ibarra Crespo 2002). Por su parte, en Perú, el fenómeno constituye el sistema tradicional de dominación y es asociado al poder ejercido por el gran terrateniente en la Sierra (Anrup 1990). En el caso colombiano, el gamonal a pesar de estar vinculado al mundo rural, no necesariamente es un gran propietario, este actor opera como eslabón entre el municipio y el departamento e, incluso, entre el municipio y el poder central. Teniendo en cuenta estos primeros supuestos, el objetivo del artículo es analizar las particularidades del fenómeno gamonal en el Nordeste de Antioquia, una zona de frontera, en donde los procesos de colonización fueron más tardíos que en las zonas céntricas del departamento, por tanto, es un escenario de configuración de redes de poder. En la documentación que ha sido revisada (fondos Gobierno Municipios y Minas y Baldíos del Archivo Histórico de Antioquia), el gamonal aparece como un actor que restringe el acceso a la tierra a campesinos pobres y colonos, lo cual implica que el gamonalismo, en esta subregión, debe ser estudiado a luz del proceso de denuncio y adjudicación de tierras baldías y los conflictos derivados de esta dinámica.
\end{abstract}

\author{
Diana Henao Holguin \\ Doctora en Historia por la Universidad \\ de Santiago de Chile. Profesora de la \\ Universidad de Santiago de Chile. \\ Santiago - CHILE \\ diana.henaoh@usach.cl \\ orcid.org/0000-0002-7821-8865
}

Palabras clave: Gamonalismo. Poder. Antioquia. Fronteras.

\section{Para citar este artículo:}

HENAO HOLGUÍN, Diana. Gamonalismo y redes de poder local en el nordeste Antioqueño, (Colombia, 1930-1953). Tempo e Argumento, Florianópolis, v. 11, n. 28, p. 127 - 155, set./dez. 2019.

DOI: $10.5965 / 2175180311282019127$

http://dx.doi.org/10.5965/2175180311282019127

\footnotetext{
${ }^{1}$ Este artículo forma parte de una investigación mayor, que corresponde a la tesis doctoral titulada "Luchas por la tierra: Conflictos agrarios en Antioquia, 1930-1953", que ha sido financiada por PFCHA/CONICYT. Beca Doctorado Nacional N 21170336 y la Dirección de Postgrado, USACH.
} 


\section{Gamonalismo and local power networks in the northeast of Antioquia, (Colombia, 1930-1953)}

\begin{abstract}
The phenomenon of gamonalismo in Ecuador is associated with a form of local political power, characterized as despotic, its livelihood is rural societies in which there is peasant subordination and dominance of large property. On the other hand, in Perú the phenomenon constitutes the traditional system of domination and is associated with the power exercised by landowners in the Sierra. In Colombia, the gamonal, despite being linked to the rural world, is not necessarily a large landowner. The gamonal acts as a link between the municipality and the department or even between the municipality and the central power. This article attempts to analyze the peculiarities of gamonalismo in the Northeast of Antioquia, a frontier area, where the colonization processes took place later than in the central zones of the department, therefore, it is a space of configuration of networks of power. In the primary sources researched (Gobierno/Municipios and Minas y Baldíos from the Historical Archive of Antioquia) the gamonal appears as an actor who restricts access to land to settlers, which implies that gamonalism in this subregion must be studied through the process of occupation of public lands and the conflicts derived from this dynamic.
\end{abstract}

Keywords: Gamonalismo. Power. Antioquia. Frontier Areas.

\section{Gamonalismo e redes de poder local no nordeste de Antioquia (Colombia, 1930- 1953)}

\begin{abstract}
Resumo
O gamonalismo é relevante para o mundo andino, no Equador o fenômeno está associado a uma forma de poder político local, caracterizado como despótico, seu meio de subsistência são sociedades rurais nas que há subordinação camponesa e predominância de grandes propriedades. Por sua vez, no Peru, o fenômeno constitui o sistema tradicional de dominação e está associado ao poder exercido pelo grande fazendeiro da Serra. No caso colombiano, o gamonal, apesar de estar ligado ao mundo rural, não é necessariamente um grande proprietário. O gamonal é o elo entre o município e o departamento e até mesmo, entre o município e o poder central. Considerando estas primeiras questões, o objetivo do artigo é analisar as particularidades do fenômeno gamonal no Nordeste de Antioquia, uma área de fronteira, onde os processos de colonização foram mais tarde do que nas áreas centrais do departamento, portanto, é um cenário de configuração de redes de poder local. Na documentação revisada (fundos Gobierno/Municipios e Minas y Baldíos do Arquivo Histórico de Antioquia), o gamonal aparece como um ator que restringe 0 acesso à terra aos camponeses e colonos pobres, o que implica que o gamonalismo nesta sub-região deve ser estudado através do processo de denúncia e adjudicação de terras públicas e os conflitos decorrentes dessa dinâmica.
\end{abstract}

Palavras-chave: Gamonalismo. Poder. Antioquia. Fronteiras. 


\section{Introducción}

El objetivo de este trabajo es analizar el papel de un actor central del mundo rural colombiano, el gamonal, quien es definido como un actor eslabón al interior de las redes de poder local y central, por tanto, funciona como eje articulador entre lo local, lo departamental y, eventualmente, lo nacional. Particularmente, en la temporalidad que abarca este trabajo 1930-1953, el fenómeno del gamonalismo adquiere unas características particulares debido al proceso de modernización estatal que fue impulsado por los liberales; que se tradujo en la centralización y en el fortalecimiento del Estado. En este contexto, estos actores son centrales en el funcionamiento del sistema político en tanto, negocian y arman redes clientelares con distintas esferas del poder. En consecuencia, el estudio de este fenómeno es fundamental cuando se analizan los procesos de formación del Estado colombiano.

Cabe anotar en este punto, que el interés de la autora por el estudio del gamonalismo, surge de un estudio mayor, que tiene por objetivo el análisis de las dinámicas en los procesos de denuncio y adjudicación de baldíos en las zonas del Magdalena Medio y Nordeste antioqueños. En estas subregiones y de manera similar al resto del país, también surgieron conflictos por la tierra entre campesinos colonos y empresarios agrícolas ${ }^{2}$; sin embargo, en las zonas de estudio, aparecen otros actores que formaron parte de esta dinámica. Uno de los que aparece de manera reiterada es el gamonal, quien, en la documentación revisada hasta el momento, está en relación con el acaparamiento y despojo de tierras a los colonos antioqueños que habitaron estas zonas de frontera en la primera mitad del siglo XX.

Ahora bien, la hipótesis que guía este trabajo, sostiene que el gamonal en el contexto de estudio va a encarnar distintas facetas. Por un lado, en ciertas ocasiones va a poner en marcha mecanismos que le permitan consolidar su expansión terrateniente, los cuales se tradujeron en el uso de la violencia y la explotación del campesinado. Sin embargo, a la vez, el gamonal en esta época también opera como intermediario, a través

\footnotetext{
${ }^{2}$ En esta perspectiva, un estudio historiográfico fundamental para comprender la dinámica de colonización a las tierras medias y bajas y los posteriores conflictos entre colonos y empresarios agrícolas por la tierra, es el de Catherine LeGrand, Colonización y protesta campesina en Colombia, 1850-1950 (LEGRAND, 1989).
} 
de la apropiación de estrategias de mediación con las autoridades y de los medios legales para obtener beneficios. Es decir, el gamonal también empezaría a adquirir algunas características propias del político profesional, relacionándose con los distintos poderes que operan en los ámbitos locales. Finalmente, otro de sus rasgos característicos sería su capacidad de armar clientelas y obtener votos para los partidos tradicionales, especialmente en el contexto de estudio, cuando el derecho al voto se extendió. A continuación, se señalarán algunos aspectos teóricos para la definición del concepto que aquí se adoptará y, posteriormente, se pasará al análisis de casos en la subregión de estudio, específicamente en los municipios de Cisneros y Yolombó.

\section{Algunos aspectos teóricos: hacia una definición del gamonal}

En la tradición rural del mundo andino, el gamonalismo es entendido como una forma de poder local rural, que está asociada a una forma de dominación tradicional del campesinado, que se basa en mecanismos despóticos y coactivos, los cuales surgen gracias a las situaciones de desigualdad social y étnica en la ruralidad. A su vez, es una forma de poder difuso y descentralizado que se da, principalmente, en un escenario en donde impera la gran propiedad. En el caso colombiano, las definiciones sobre el gamonal están más asociadas a su papel como intermediario. Semejante al caciquismo en México, el gamonalismo en Colombia equivaldría a un jefe político ${ }^{3}$, que es, en parte, un intermediario entre el propietario de fincas y los campesinos o jornaleros que trabajan en ellas. No obstante, su función no se restringe al mundo de la hacienda, dado que el gamonal también sería un mediador entre el pueblo rural y las instituciones del estado. Carlos Miguel Ortiz, define al gamonal de la zona cafetera del Quindío como “... un propietario de muchas fincas y casas, un comprador de café o proveedor de mercancías, relacionado permanentemente con el municipio, pero no necesariamente el más pudiente de todos" (ORTIZ, 1985, p.48 ). Para este autor, el gamonal sería una especie de jefe veredal cuyos rasgos más característicos son la capacidad de resolver los problemas

\footnotetext{
3 Sobre la importancia de los jefes políticos en México, Romana Falcón (FALCON, 2015) publicó un trabajo en el que releva la importancia de este sujeto en los procesos de negociación con el poder central y las regiones. Aquí, la autora estudia las tensiones entre las distintas instancias del poder y analiza al jefe político como un eslabón en la cadena de mando.
} 
de los campesinos en las veredas y la posibilidad de mediar ante las autoridades de los pueblos, es decir representar a los campesinos frente a las instancias del Estado.

Sin embargo, otro de los rasgos característicos del gamonal colombiano, sería el de armar clientelas con el fin de obtener votos para uno u otro de los partidos tradicionales. Durante el siglo XIX, los gamonales tuvieron la función de organizar ejércitos durante las guerras civiles y de obtener electores, sobre todo a medida que se iba extendiendo el derecho al voto; por tanto, tenían una labor fundamental en la construcción de redes clientelares (DEAS, 2006). En consecuencia, gamonales y caciques fueron importantes agentes políticos, que manipularon los votos y las elecciones a nivel local, asimismo fueron gestores importantes de la violencia bipartidista durante el siglo XX. (BETANCOUT Y GARCíA 1990). Para el caso de los Santanderes, los gamonales garantizaban el triunfo electoral de sus partidos, mediante el ejercicio de la coacción, persiguiendo a los oponentes de sus partidos, politizando la policía municipal, creando policías cívicas como sus brazos armados y apoyando a bandoleros de sus propias colectividades (VÁZQUEZ, 2017).

Es así como el fenómeno gamonal se ha definido en dos sentidos, por una parte, como intermediario entre las necesidades del campesinado y los poderes locales o regionales; es decir como eslabón entre el poder local y regional y a veces el central. Asimismo, es definido en función de armar clientelas, obteniendo votos para los partidos que representan. Sin embargo, en el contexto de análisis de este artículo se encuentra que el gamonal, también, está asociado al acaparamiento de tierras, de manera similar a los casos peruano y ecuatoriano, los gamonales serían actores centrales en la expansión terrateniente.

En el caso ecuatoriano, el gamonalismo corresponde a un periodo histórico que va desde mediados del siglo XIX y hasta los años sesenta del siglo XX, momento en el que se dan los cambios necesarios para una reforma agraria que erosionó la gran propiedad, escenario por excelencia del gamonalismo (IBARRA, 2002). A su vez, durante este periodo de auge del fenómeno, el Estado era altamente descentralizado, por tanto, era posible la prevalencia del componente despótico encarnado por el gamonal, el cual va perdiendo su importancia ante el fortalecimiento de un Estado centralizado, que adquiere 
la capacidad de penetrar en la sociedad civil. En Ecuador, el concepto de gamonal sufre un importante giro en la década del veinte del siglo pasado. Antes de este momento, la novela costumbrista ecuatoriana había definido al gamonal como un campesino acomodado o un mediano propietario, que cumplía funciones de mando en una cabecera parroquial, aunque paralelamente estaba subordinado política y socialmente a las elites regionales. A su vez, el gamonal ecuatoriano era indispensable para mantener bajo control a los indígenas, así como para lograr votos en épocas de contienda electoral. Sin embargo, esta primera concepción del gamonal fue modificada por la que se asocia más a un actor proveniente de las elites regionales, lo que lo ponía en los niveles superiores del ejercicio del poder rural, siendo una de sus manifestaciones la dominación étnica, cuyo poder se basaba en el control de la tierra. (IBARRA, 2002, p. 141)

Ahora bien, en el Perú y de manera similar al caso ecuatoriano, las condiciones estructurales para la aparición del gamonalismo fueron la desaparición del sistema colonial y la debilidad del Estado central. Aquí, el gamonalismo aparece a mediados del siglo XIX, aunque tuvo su apogeo en las últimas décadas de ese siglo y hasta la década del treinta. Este fenómeno fue producto de la legislación republicana, que propició la consolidación del latifundio, lo cual devino en un proceso de desarrollo de poderes locales y regionales que operaban de manera autónoma respecto del poder central (CONTRERAS, 1980, p. 24). El gamonal peruano es asociado al gran terrateniente de la sierra cuyo poder incluye el control no solo de los recursos económicos, sino también de los políticos, jurídicos y culturales.

Los rasgos generales del gamonal, en este contexto, fueron: a) la utilización del trabajo de los peones en las haciendas; b) El empleo del trabajo de campesinos libres para la construcción de obras públicas en beneficio de los terratenientes y c) La usurpación de las tierras de las comunidades indígenas. (ANRUP, 1990).

Sin embargo, estas características podían variar de una provincia a otra, asimismo las estrategias de control sobre la población indígena podían variar de acuerdo con el contexto. Contreras Hernández (CONTRERAS, 1980) señala que, para el caso de Chinchero en el Cuzco, los rasgos más recurrentes de la actuación del gamonalismo fueron en primer lugar, la apropiación de terrenos privados, comunales y municipales, los 
cuales eran anexados a las haciendas por medio del fraude, usando la autoridad pública para el logro de fines personales. El segundo rasgo corresponde a la apropiación de bienes diversos para el enriquecimiento personal de los gamonales, siendo estos bienes preferentemente los animales de los campesinos (como borregos, cerdos, gallinas) u otros bienes que pertenecían a la municipalidad. Finalmente, los gamonales se apropiaron de la fuerza de trabajo de los campesinos de manera gratuita.

Las estrategias para la ejecución de estas acciones fueron distintas, en el caso de Chinchero, los gamonales se valieron de la represión directa a los campesinos, la cual podía ser ejercida gracias a la protección que gozaban por parte de las autoridades del distrito. Sin embargo, la coerción hacia el campesinado no era la única estrategia; también en el Cuzco, Roland Anrup (ANRUP, 1990) afirma que dentro de las haciendas operó el compadrazgo, estrategia que permitió la reproducción de los pactos de deferencia y lealtad entre el patrón, análogo a la figura del padre, y los campesinos. Gracias al compadrazgo, el patrón era admirado, respetado, pero también era temido; por lo tanto, la hacienda era una estructura compleja dentro de la que campesinos y hacendados estaban ligados por sentimientos fuertes, que eran reforzados por medio de intercambios simbólicos asimétricos, en los que ambas partes adquirían obligaciones.

No obstante, el compadrazgo no tuvo el mismo peso en toda la sierra peruana; en Arequipa por ejemplo, el gamonalismo operó a través de la explotación y coerción al campesinado, por lo que los campesinos se valieron de medios legales y de otras estrategias para frenar la expansión terrateniente. Dentro de estas últimas, cuentan la de pertenecer a una comunidad campesina, lo cual les permitía defender con mayor éxito su tierra. A su vez, en Arequipa, los campesinos se beneficiaron de las contradicciones al interior de la clase gamonal, que no funcionaba como un bloque cohesionado, por tanto, ejercían poder solo dentro de su ámbito local. En consecuencia, los campesinos se aprovecharon de las luchas entre las familias de notables que competían por la apropiación de tierras de los indígenas, vendiendo tierras al mejor postor (MANRIQUE, 2001, p. 264).

A partir de la lectura del caso peruano, se observa que los campesinos, en Arequipa, pudieron generar mayores lazos de solidaridad, lo que les permitió interponer 

las que el compadrazgo operaba como estrategia de dominación, dado que, se generó una situación de dependencia con el patrón, en la que cada campesino competía por ser el "hijo predilecto" con los beneficios que esto traía, lo que aisló a los individuos de sus colectividades sociales, por tanto, las relaciones horizontales eran débiles 0 , prácticamente, inexistentes.

Análogo al fenómeno del gamonalismo se encuentra el caciquismo mexicano, cuya bibliografía es amplia. En el caso mexicano, la figura corresponde más a un jefe político que se convierte en un intermediario, cuya función principal es organizar el poder local o regional a través de mecanismos clientelares o despóticos. Romana Falcón define al cacique como "alguien que domina la vida política y en ocasiones la económica de determinada región, frecuentemente por medio de procedimientos extralegales" (FALCÓN, 1984, p.15). La autora reconoce que, en México, durante la Revolución y, específicamente, tras la promulgación de la constitución de 1917 se establecieron, al menos formalmente, las bases para la centralización del poder, lo que se tradujo en un proceso largo y contradictorio en el que los caciques tuvieron un papel fundamental, permitiendo que las autoridades federales dieran alguna estructura a la vida política nacional. Durante la década del veinte y del treinta, los caciques mexicanos continuaron adueñados de algunas regiones del país; sin embargo, después de la Segunda Guerra Mundial, su poder regional entraría en decadencia, debido al avance de la acción del poder central que iba en detrimento de los mecanismos de mediación y control impuestos por los caciques.

Ahora bien, si la función del cacique es la de intermediario, conviene resaltar los mecanismos de mediación que utiliza, ya que las formas de dominación no descansan, exclusivamente, en la coacción o en la manipulación que ejerce. A diferencia del caso ecuatoriano y peruano, ahora estamos frente a un escenario de intercambio; por ello el concepto de clientelismo adquiere relevancia porque pone el acento en dicho intercambio informal de bienes y servicios entre individuos de poder y status desiguales. 
Este aspecto es relevante al momento de analizar el caso que nos atañe; si bien el gamonal en el contexto de estudio puede llegar a usar métodos coactivos, también, usa mecanismos de negociación.

Cabe destacar entonces el rol de los caciques como cabezas de la política local y regional, en el sentido que le otorga François-Xavier Guerra, quien encuentra en estos actores el elemento que articula las formas modernas de la política y las realidades que fueron heredadas del Antiguo Régimen. Para Guerra es aquí donde radica el fundamento del caciquismo "En la existencia de poderes, de imaginarios y de valores de tipo antiguo, en sociedades en que el sistema legal de referencias de tipo moderno niega a los poderes de tipo antiguo toda legitimidad" (GUERRA, 1992, p. 184). En consecuencia, estos fenómenos son paradojales en tanto se dan en sociedades muy tradicionales con regímenes políticos modernos.

La definición de gamonal, que aquí se toma, transita a través de estas tensiones planteadas por Guerra, en las que si bien, el gamonal ejerce el poder por medios despóticos, a su vez, en las zonas de frontera en donde se presenta el fenómeno, estos actores también se apropian de unas estrategias de negociación; que implican relacionarse no solamente con la localidad y el mundo de la hacienda, sino también con las autoridades departamentales y con los distintos poderes municipales: el judicial, el civil y el clerical, configurando redes de poder local. A su vez, se apropian de la legislación para obtener beneficios, especialmente en lo que tiene que ver con el acaparamiento de tierras. En consecuencia, el gamonal en la zona de estudio transita entre los procesos de expansión terrateniente y su rol como intermediario.

En la documentación que ha sido revisada se usa, indistintamente, el término gamonal para referirse a quien acapara tierra y a quien sería más bien un intermediario o cacique político. Sin embargo, se ha percibido a través del análisis de la documentación, que cuando puede distinguirse la voz de los campesinos, estos usan el término gamonal para referirse a quien se apropia de sus tierras y mejoras. Paralelamente, el término es usado para referirse a quien sería más bien un articulador de redes clientelares, por medio de la dominación del campesinado para obtener votos de él. 


\section{Gamonales en una zona de frontera en Antioquia.}

En el estudio de las relaciones entre colonización y conflicto aparecen diversos actores que se vinculan en la dinámica de los procesos de denuncio y adjudicación de baldíos. La historiografía agraria en Colombia, hasta el momento, ha identificado dos actores centrales en el proceso de colonización y los conflictos derivados de ella: los colonos y los empresarios agrícolas. En este sentido, Catherine LeGrand (LEGRAND, 1988) afirma que la ocupación de tierras se dio en dos etapas, una primera en donde hay un movimiento de colonos hacia las tierras públicas, generando la apertura de nuevas zonas agrícolas y una segunda etapa en donde los empresarios agrícolas consolidan nuevas haciendas, por medio de la apropiación de la tierra y del trabajo de los campesinos. Este proceso demuestra que la expansión de la frontera agrícola trajo consigo conflictos entre campesinos y hacendados, los cuales hacia la década del treinta desembocarían en un movimiento agrario que reivindicaba el derecho a la tierra y a la modificación de los sistemas de trabajo. Sin embargo, al momento de analizar las dinámicas regionales, se observa que este proceso tiene matices a nivel local y que la participación de otros actores es fundamental. Por ejemplo, al hablar de campesinos debe reconocerse la existencia no solo de campesinos sin títulos formales de tierra, sino también de medianos y pequeños propietarios. A su vez, como actores intermedios están los tinterillos y los abogados, quienes por medio de la ley y del conocimiento que sobre la misma tienen, ponen a operar la maquinaria del Estado, implementando la legislación. Por su parte, los empresarios agrícolas también poseen diferenciaciones, hay elites departamentales, pero también locales, y estas entran en disputa por el control de la tierra y los proyectos políticos que cada grupo defiende. Finalmente, los gamonales adquieren importancia, como actores intermedios en estas dinámicas, ya sea restringiendo la ocupación de tierras o tejiendo las redes de poder local, a veces en oposición a los proyectos políticos del centro y otras veces en consonancia con estos.

El contexto de aparición de estos actores son, principalmente, las zonas de frontera, lo que nos enfrenta con un escenario de configuración territorial, en donde cuenta la conformación de redes de poder local. Particularmente, la región del Nordeste (junto con la del Magdalena Medio y Bajo Cauca) constituyó, desde el siglo XIX, una preocupación para las elites del centro de Antioquia, quienes movidas por los recursos 
naturales que allí existen, quisieron generar una colonización "planeada", en donde se reprodujeran los valores culturales del centro del departamento. Sin embargo, la expansión de las elites del centro ocurrió en la primera mitad del siglo XX, cuando los avances en comunicación y transporte permitieron explotar la tierra y conformar haciendas ganaderas y agrícolas. (ROLDÁN, 1992).

Los procesos de colonización en Antioquia facilitaron la emergencia de "nuevas elites". Algunos de los individuos que se desplazaron consiguieron riquezas e influencia política en los territorios a los que llegaron, y aquellas familias que triunfaron en la construcción de redes comerciales combinadas con inversiones en minería, industria, ganado y haciendas pudieron extender sus operaciones a la capital del departamento y a través de asociaciones de negocios y el matrimonio, el "poder regional" se fue consolidando a la par del proceso de integración del Departamento (ROLDÁN, 1992).

La subregión del Nordeste ha sido una zona abocada principalmente a la extracción de minerales. Su proceso de poblamiento ocurrió desde las primeras décadas del siglo XIX y estuvo vinculado a la extracción aurífera, paralelamente a la explotación de minas comenzó un proceso de adjudicación de tierras baldías. A finales del siglo XIX, en el municipio de Segovia se estableció la Frontino Gold Mines, una compañía minera estadounidense, que generó una economía en torno al oro, de ahí que la mayoría de los habitantes económicamente activos en Segovia, trabajaran para la Frontino y vivieran en el campamento minero de la empresa. No obstante, el Nordeste antioqueño también se compone de municipios que no están destinados, exclusivamente, a la extracción de oro, sino que también poseen una actividad agrícola importante. Yolombó, Amalfi, Cisneros, Santo Domingo y San Roque conforman ese "otro" Nordeste. A diferencia de Segovia y Remedios, no soportaron la misma influencia de la compañía extranjera, lo que significa que los procesos de ocupación de la tierra revistieron unas características distintas, que se tradujeron en una conformación particular de redes de poder local. Además, estos últimos municipios sirvieron de despensa para las zonas mineras, por tanto, sus habitantes combinaron la minería y la agricultura dentro de sus actividades económicas, lo que hizo que allí la tierra tuviera una importancia mayor, en comparación a sus vecinos Remedios y Segovia. 
Este escenario, en el que se conjugan colonización (lo que conlleva la conformación de pequeñas, medianas y grandes propiedades) y conflicto, es el escenario por excelencia de la aparición del fenómeno gamonal. Estos actores poseen una estrecha relación con estos procesos de ocupación de la tierra. Es en este contexto de colonización y adjudicación de tierras que los gamonales ejercen su rol, restringiendo el acceso de campesinos a la titulación, no solamente a través de medios coactivos, sino también a través de la apropiación y puesta en funcionamiento del aparato legal. Una experiencia similar a la del Nordeste fue la del Valle del Cauca, estudiada por Darío Betancourt y Martha García, quienes sostienen que en este departamento hubo un manejo electoral del campesinado por parte de gamonales y caciques en el contexto de los procesos de adjudicación de baldíos. (BETANCOURT, GARCIA, 1990) No obstante, a nuestro juicio, afirmar que los gamonales manipularon a amplios sectores rurales, resta racionalidad al accionar de los campesinos y obvia las estrategias de negociación que pudieron tener distintos grupos en el mundo rural.

En la documentación que ha sido revisada correspondiente a los fondos de Gobierno Municipios y Minas Baldíos (ambos reposan en el Archivo Histórico de Antioquia), se pueden identificar distintos memoriales, no solo de los vecinos notables y autoridades locales, sino también de campesinos que se organizan para demandar sus derechos frente a las autoridades departamentales. Es en esta documentación cuando empiezan a ser mencionados estos "gamonales", Ilamados también “caciques” o "jefes políticos", siendo empleados estos dos últimos términos principalmente para referirse a los sujetos que se relacionan con la construcción de clientelas. Particularmente, en el Nordeste antioqueño, la definición del gamonal corresponde a hombres oriundos de la zona o que habitan en los municipios de la subregión; además, son propietarios de tierras y se relacionan con los poderes locales y departamentales. Pueden tener influencia en la gestión de las políticas públicas locales y participar directamente de los cargos públicos de sus localidades. Como se verá a continuación, algunos de ellos están relacionados directamente con el acaparamiento de tierras y entrarán en conflicto directo con el campesinado. 


\section{Entre la coacción y la legalidad. El caso de la Hacienda "Nus o Zarzal”}

Ya se ha mencionado más arriba que el fenómeno del gamonalismo en el caso peruano y ecuatoriano está asociado a una forma tradicional de dominación, en la que el gamonal rige la vida y el destino del campesinado a través de mecanismos de dominación, en donde impera la explotación étnica; en consecuencia, en este contexto los campesinos difícilmente pudieron generar estrategias para detener la expansión terrateniente, dado que la dominación era ejercida a través de la coacción y el compadrazgo. Sin embargo, esta característica no es aplicable al caso colombiano, en tanto resta agencia al campesinado y no permite observar cuáles han sido sus acciones frente al despojo, las cuales van de la utilización de los medios legales, pasando por lo que James Scott (SCOTT, 1985) denomina formas de resistencia cotidiana, hasta el uso de la violencia.

Al abordar la documentación se observa que, si bien hay unos mecanismos de dominación basados en la coacción, a su vez, los campesinos en Colombia y, particularmente, en Antioquia han construido estrategias de resistencia. Una de las estrategias más extendidas ha sido la apropiación de la legislación de baldíos, la cual les ha permitido hacer reclamaciones a las autoridades departamentales o nacionales, aunque no tanto a las locales, ya que los sectores populares tenían desconfianza de los administradores municipales, debido a sus constantes abusos y los vínculos entre la administración local, gamonales y vecinos notables.

En un memorial de 1940, firmado por los colonos de Yalí, se observa cierto grado de organización del campesinado, lo que otorga agencia a sus acciones; el memorial buscaba reivindicar el derecho a la ocupación de tierras baldías: “Como los más conscientes vemos que esos "señorones" no tienen derecho a tanta cantidad de terreno virgen, puesto que no han cultivado ni la vigésima parte". ${ }^{4}$ Frente a la presentación de estos memoriales, una de las respuestas fue la violencia, que era ejercida "desde arriba": "los presuntos dueños de que damos cuenta en el análisis anterior, nos amenazan armados de escopetas y machetes, asegurando quitar la vida al que intente explorar". 5

\footnotetext{
${ }^{4}$ Las cursivas son nuestras. Archivo Histórico de Antioquia (AHA). Secretaría de Hacienda. Minas y Baldíos, Caja 5134, Carpeta 3, f. 65.

${ }^{5}$ AHA. Secretaría de Hacienda. Minas y Baldíos, Caja 5134, Carpeta 3, f. 65.
} 
Sin embargo, como veremos más adelante, la violencia no es el único mecanismo que era empleado por los gamonales.

Uno de los casos más emblemáticos encontrados hasta el momento, corresponde al de la Hacienda “Nus o Zarzal”, ubicada en Cisneros. Aquí, hubo una oposición colectiva de 341 colonos quienes afirmaban llevar ocupando parcelas de tierra en la hacienda por más de veinte años, con casas de habitación y plantaciones. ${ }^{6}$ Para contextualizar este caso hay que remitirse al año 1929, cuando en el juicio de sucesión de la señora Flora Martínez viuda de Moreno, se decidió rematar a solicitud de los herederos, la hacienda “Nus o Zarzal”, con una extensión de 768 hectáreas y, estratégicamente, ubicada por lindar con la vía del Ferrocarril y con el camino hacia Yolombó, lo que la comunicaba con importantes vías del Departamento. Quienes obtuvieron la hacienda en el remate fueron Rafael Castaño, Heliodoro Barrera, Francisco Echeverri y Félix Amaya, habitantes del municipio e identificados como notables. En la mañana del 6 de febrero de 1930, se procedió a realizar la diligencia de entrega, sin embargo, durante este proceso oficial, el Doctor Clodomiro Ramírez solicitó:

[...] ]el uso de la palabra para hablar en nombre de las personas que concurrieron a la diligencia con el carácter de colonos de la expresada finca y le fue concedida, por lo cual el Dr. Ramírez, leyó los autos del Honorable Tribunal Superior[...] concluyendo el Dr. Ramírez en que el juzgado no podía despojar a los colonos y que se oponía a la entrega de la finca en nombre de ellos y presentó una lista de trescientos cuarenta y uno colonos que poseen terrenos de la finca aludida. ${ }^{7}$

La imposibilidad de hacer la entrega efectiva de la hacienda significó el inicio de un ciclo de violencia, que se intensificó a partir de julio de 1931, cuando el Tribunal Superior de Antioquia dispuso una entrega parcial, por medio de la cual, dejaba en posesión a cada

\footnotetext{
${ }^{6}$ Cabe anotar que la fundación del municipio de Cisneros (1910) estuvo liderada por los obreros, provenientes de distintos lugares del departamento, quienes se establecieron en la zona con el fin de trabajar en la construcción del Ferrocarril de Antioquia; este hecho pudo ayudar a la configuración de estrategias organizativas por parte de sectores populares.

7 Llama la atención el papel del Dr. Clodomiro Ramírez en el caso. Ramírez, además de ser abogado titulado de la Universidad de Antioquia, ejerció diferentes cargos públicos departamentales y fue Gobernador de Antioquia en dos ocasiones. Es de suponer que asumió la vocería de los colonos, puesto que, el día de la diligencia de entrega, además de representar a los colonos, iba como apoderado de Emilio Restrepo, empresario antioqueño del centro, quien donó parte de los terrenos de su hacienda para la construcción de la estación del ferrocarril de Cisneros. Se menciona en la documentación, que Restrepo le dio poder a Ramírez, porque su hacienda era colindante con la hacienda involucrada en el pleito. AHA. Secretaría de Hacienda. Minas y Baldíos, Tomo 5120, Carpeta 3, f. 3, 1932.
} 
uno de los colonos del terreno que poseían, con sus mejoras. Si bien, hasta ese momento hubo expresiones de violencia entre los grupos enfrentados, después de este hecho la violencia se desató con más fuerza entre gamonales y colonos, los primeros, intentando desalojos y los segundos resistiéndose al despojo. El grupo de gamonales, encabezado por Rafael Castaño, desplegó estrategias para el desalojo, entre las que cuentan la construcción de cercos, la invasión con ganados a las mejoras de los colonos, la destrucción de casas de habitación y las amenazas que eran comunicadas a través de los peones que trabajaban en la hacienda. Sin embargo, estas acciones violentas no fueron exclusivas de "los de arriba"; los colonos también dieron respuesta a estas acciones, a través de daños a los animales que echaban a sus sementeras, ocupaciones de hecho (tomando más terreno del que les correspondía), destrucción de cercos y rastrojos; a lo que se suma el asesinato de un peón que trabajaba para Rafael Castaño perpetrado por uno de los colonos, lo que sin duda intensificó la violencia. ${ }^{8}$

Cabe anotar en este punto, que las acciones violentas que desplegaron los gamonales tienen una racionalidad tras de sí, especialmente en lo que tiene que ver con la destrucción de casas de habitación y sementeras, puesto que, estos bienes eran obligatorios al momento de realizar los trámites legales para la adjudicación de tierra baldía, por tanto, la destrucción de casas y cultivos fue una estrategia ocupada en distintos territorios nacionales, con el fin de impedir que los colonos obtuvieran de manera legal la adjudicación de sus mejoras.

No obstante, la violencia no fue el único medio que usaron los gamonales para consolidar la expansión terrateniente y atomizar las estrategias organizativas de los colonos de la hacienda Nus. Rafael Castaño y su grupo se valieron también de medios legales, para lograr sus objetivos. El primer medio legal del que se valieron fue el de las querellas, las cuales interponían frente a la alcaldía o la Jefatura de policía. A través de estos denuncios se acusaba a los colonos por emplear formas de resistencia, que les

\footnotetext{
${ }^{8}$ Si bien, este asesinato es referido en este memorial que fue redactado por los colonos, parece ser una estrategia del grupo para hacer ver a las autoridades departamentales el alto nivel de conflictividad que había tomado este pleito, por ello afirman: “ya cansado uno de los colonos de tanta humillación, resolvió según dicen disparar su escopeta contra un trabajador de los señores rematadores, dejándolo muerto en el sitio". AHA. Secretaría de Hacienda. Minas y Baldíos, Tomo 5120, Carpeta 3, f. 2-4, 1932.
} 
Aparecía un animal herido de los rematadores y todas las sospechas recaían sobre los colonos... si aparecía un potrero ardiendo, así fuese por motivo de una chispa de la locomotora, el abogado de los rematadores elevaba denuncio señalando como autores a aquellos colonos... si un colono trataba de echar una roza, el denuncio, si aparecía un palo cortado, el denuncio... ${ }^{9}$

El segundo medio legal fue la apelación contra los autos del Juzgado del Circuito de Yolombó, que ordenaban cumplir el mandato del Tribunal Superior de Antioquia, por medio del cual se permitía a los colonos continuar la ocupación de sus terrenos. A esto se suma las oposiciones para suspender los denuncios formales elevados por los colonos, siendo esta una estrategia efectiva en el acaparamiento de tierra. Tanto campesinos como gamonales, se valieron del aparato legal, particularmente de la legislación de baldíos, que especificaba los procedimientos formales para hacer los denuncios de tierras públicas. Aquí, hay que recordar que la política de reforma agraria en Colombia se ha basado en la adjudicación de terrenos baldíos. Esta dinámica ha sido recurrente a lo largo del siglo XX; por tanto, campesinos y empresarios agrícolas se han apropiado de la legislación, con el fin de acceder a la tierra. La ley de baldíos que regía en ese momento decretaba que:

toda persona puede adquirir como colono o cultivador, título de propiedad sobre los terrenos baldíos en donde se haya establecido con casa de habitación y cultivos permanentes, como plantaciones de café, cacao, caña de azúcar, o sementeras de trigo, papa, maíz, arroz, etc., en una extensión no mayor de diez (10) hectáreas y otro tanto de lo cultivado (COLOMBIA, Ley 47, 1926, Diario Oficial No 20.346, Bogotá)

Para obtener esta adjudicación bastaba con dirigir un memorial al Gobernador del Departamento en que estuviera ubicado el terreno. Esto se hacía frente al Juez Municipal correspondiente, quien con citación del Personero Municipal tomaba la declaración de tres testigos “hábiles, de buena reputación y vecinos del lugar”. Para elaborar el memorial debía seguirse un modelo de interrogatorio que constaba de ocho preguntas entre las que se incluían si los testigos conocían el terreno, si el denunciante se hallaba

\footnotetext{
9 AHA. Secretaría de Hacienda. Minas y Baldíos, Tomo 5120, Carpeta 3, f. 3, 1933.
} 
establecido con casa de habitación y cultivos permanentes, el número de hectáreas del predio denunciado, sus límites, si dentro del lote no había establecidos otros colonos, no existían minas de aluvión, no estaba dentro de bosques nacionales, ni sobre vía pública en extensión mayor de 2.5 kilómetros. Si se cumplía con estos requisitos se procedía a realizar la diligencia de entrega.

Estas leyes que iban dirigidas a facilitar la adjudicación de terrenos a pequeños propietarios, es decir fincas no mayores de 20 hectáreas, por lo tanto, fueron apropiadas por los colonos, quienes por su propia cuenta o con la ayuda de tinterillos, elevaron denuncios de tierras a la Gobernación de Antioquia. El procedimiento parecía sencillo; sin embargo, podía llevar meses o incluso años en que las tierras ocupadas fueran adjudicadas. A esto se suma, que durante la década del treinta se decretaron varias leyes de tierras, lo que hacía que incluso las autoridades departamentales desconocieran el proceso formal de adjudicación.

A través de este proceso los colonos lograban la adjudicación provisoria que otorgaba la Gobernación de Antioquia, sin embargo, al momento de la diligencia oficial de entrega del lote, se presentaban las oposiciones por parte de gamonales, empresarios agrícolas (o sus representantes, mayordomos o abogados) e incluso colonos. En el caso de la hacienda Nus, Rafael Castaño se opuso por lo menos ocho veces a los procesos de adjudicación elevados por pequeños colonos. Estas oposiciones las hizo presentando el título que se remontaba al año 1866, cuando a cambio de bonos territoriales se adjudicó la hacienda a los hijos del Teniente Coronel Joaquín Rodríguez. Es decir, Rafael Castaño poseía copia del título y la diligencia de remate por medio de la cual había obtenido la finca junto a otros compradores. A través de esta estrategia interfirió en el proceso para que a campesinos colonos les fueran adjudicadas las parcelas que venían cultivando desde hacía dos décadas. Esta situación se vio reforzada por la ley. Hasta la década del treinta, antes de la promulgación de la ley de tierras (COLOMBIA, ley 200, 1936), el artículo 10 de la Ley 71 de 1917 seguía en vigencia; este ordenaba respetar los títulos de propiedad, por tanto, las autoridades administrativas podían abstenerse de dictar la resolución de adjudicación, sin tener que examinar la "bondad de los títulos", así, no se entraban a resolver controversias, ya que esto era competencia del poder judicial. Es 
decir, esta situación solo podía ser resuelta frente a los juzgados correspondientes. Esto se traducía en que las entregas de los lotes no se hacían, quedando el campesino sin la adjudicación que le correspondía y propenso a la evicción.

Finalmente, el otro mecanismo que fue usado por los gamonales para desalojar a los colonos, además del legal, fue valerse de su estatus en el municipio, intentando cambiar a las autoridades civiles que más pudieran ayudarles a propiciar el despojo. Rafael Castaño y su grupo, formaban parte de los vecinos notables de Cisneros, incluso el mismo Castaño durante la década del veinte, fue miembro del honorable Concejo Municipal. Es por eso, que en alguna de la documentación encontrada en el fondo Gobierno Municipios de 1932 y 1933 se encuentran memoriales, que fueron redactados por Castaño, Echeverri y Amaya, en los que solicitan el cambio de alcaldes, particularmente de Luis E. Angulo, quien quería hacer cumplir el mandato de no desalojar a los colonos. En carta fechada el 30 de agosto de 1932, que fue enviada al Gobernador de Antioquia, el alcalde le explica:

La única causa del porqué de la mal querencia contra el actual personal de la Alcaldía, que no es otra, fuera de la de haber dado cumplimiento a una sentencia de la Jefatura General de Policía poniendo en posesión unos colonos de un lote de terreno en un globo o lote mayor que desde hace más de cuatro años se disputan con encarnizamiento un crecido número de colonos que poseen pequeños lotes... y cuatro gamonales... han empleado cuantos medios les ha sido posible para echarlos, lo que ha motivado homicidios y muchos otros delitos contra la propiedad... dícese aquí, que los rematadores pretenden a todo trance que se nombre un individuo a quien ellos puedan manejar. ${ }^{10}$

Esta primera ejemplificación, permite observar la utilización de distintas estrategias por parte de gamonales, que van desde el conflicto, pasando por las acciones violentas, hasta el manejo de las redes locales de poder para el cambio de autoridades locales, que les permitieran cumplir sus objetivos de acaparamiento de tierras. Ahora bien, ¿Qué diferencia existe entre estos gamonales y los empresarios agrícolas? A pesar de compartir algunas características, como el tener "recursos económicos y conexiones políticas"11 (LEGRAND 1988, p. 62), los gamonales parecen tener una mayor capacidad de

\footnotetext{
${ }^{10}$ AHA. Secretaría de Gobierno. Gobierno municipios, Cisneros, Tomo 395, f. 246, 1932.

${ }^{11}$ Catherine LeGrand define a los empresarios agrícolas como pertenecientes a sectores medios y altos de la
} 
relacionarse con los poderes locales. Al habitar los municipios en donde se ubican los baldíos (a diferencia de los empresarios agrícolas antioqueños, que provenían de Medellín) es probable que tuvieran un mayor poder de negociación y de construcción de redes clientelares. En el caso de Antioquia, los empresarios agrícolas, provenientes principalmente de Medellín, tenían intención de conformar haciendas ganaderas (en el Nordeste y sobre todo en el Magdalena Medio) y para ello usaron medios legales, como la compra de mejoras a los colonos y el denuncio de tierras, a través de la legislación de baldíos. $^{12}$

Ahora bien, en la documentación, cuando puede distinguirse la voz de los campesinos, los mismos se refieren a gamonales, cuando hablan de personas del municipio, que, gracias a su influencia en la administración local, lograban desalojarlos de sus mejoras a través de las vías legales y la violencia. Rafael Castaño, sería uno de estos gamonales, un vecino notable, que se relacionaba con los funcionarios locales y que buscaba, por medio de la fuerza, consolidar una hacienda. Estas características lo asemejarían a los gamonales que ocuparon la sierra peruana, en donde estos actores fueron centrales en la expansión terrateniente. Sin embargo, Castaño no se preocupó de construir una base social que le permitiría continuar ocupando cargos en la administración local o extender sus redes clientelares, por ello en la documentación sobre Cisneros, no vuelve a parecer de manera central, solo firmando algunos memoriales de vecinos para la remoción de alcaldes. En Cisneros y, especialmente, a partir del gobierno de Alfonso López Pumarejo (1934-1938) serán otros caciques los que se consolidarán como jefes políticos locales, abanderados principalmente del ala lopista del partido liberal.

sociedad colombiana. Algunos eran profesionales que provenían de importantes familias desde la colonia y otros eran individuos en ascenso, que buscaban educarse en Medellín o Bogotá. Finalmente, también había caciques políticos, tenderos y prestamistas que eran conocidos en los pueblos. (p. 62) Sin embargo, en el contexto que estamos estudiando, los gamonales no serían equiparables a los empresarios agrícolas, a pesar de ser ambos, actores centrales en los procesos de despojo de tierras, aquí se considera que hay unos matices en las definiciones de cada uno de ellos.

${ }^{12}$ Hasta el momento se han revisado los archivos de la Hacienda La Morela (de la familia Escobar Villegas ubicada en Puerto Berrío) y la Hacienda La Carolina (de la familia Ospina Vásquez en Yolombó) en ambos archivos al revisar la correspondencia se observa que estos empresarios medellinenses buscaban conformar sus empresas por medios legales. Aunque esto no significa que los conflictos con colonos quedarán excluidos o que no hubiese en algunas ocasiones acciones violentas; sin embargo, parece que no hicieron un uso tan sistemático de la violencia, a diferencia de los gamonales oriundos de los municipios. 
Como se verá a continuación, hay otros gamonales que sí adoptaron un papel de intermediarios y de políticos profesionales y cuya relación con los partidos políticos tradicionales fue mayor, por tanto, fueron más eficientes en la construcción de redes de poder local. Además, al menos en la documentación revisada, si bien tuvieron conflictos con colonos, prefirieron usar las vías de derecho para la resolución de los mismos.

\section{Gamonales en Yolombó: El intermediario}

Para el caso de Yolombó se identificaron dos personajes que pueden ser clasificados como gamonales en tanto empiezan a moverse dentro de las redes de poder; ellos son Carlos Fidel Cano y Luis Eduardo Vanegas Franco, ambos propietarios de tierras y adscritos al partido liberal, siendo esta última característica significativa, puesto que, la pertenencia a alguno de los dos partidos tradicionales, nos pone frente a un escenario de configuración de redes clientelares y de negociación con otros poderes locales.

Las primeras noticias que se tienen de Fidel Cano son de 1931, cuando fue nombrado administrador de la finca El Saltillo, que estaba dividida en 24 acciones de las cuales 23 le pertenecían al señor Ricardo González y lo restante a varios colonos. Carlos, Jesús y Rafaela Tobón y otros colonos llevaban ocupando estos predios durante dos décadas; allí, poseían casas de habitación, labranzas y mejoras. Sin embargo, Cano como administrador de la finca les prohibía continuar la ocupación. Ante esta situación los colonos enviaron una consulta al Secretario de Gobierno Departamental, en donde preguntaron acerca de la validez de los medios que fueron usados por Cano para desalojarlos, consistentes principalmente en memoriales en donde se solicitaba la presencia de agentes de policía para "evitar vías de hecho”. A esta acción se suma la prohibición de dejar pastar ganado, propiedad de los colonos, en los predios de la finca. Finalmente, los colonos consultan si "las resoluciones que los administradores dicten para poder administrar correctamente el bien común, tienen que hacerlas saber en persona a los comuneros, o lo hacen por conducto de la Alcaldía o el Juez que lo nombró”. ${ }^{13}$

\footnotetext{
${ }^{13}$ AHA. Secretaría de Gobierno. Gobierno Municipios, Yolombó, Tomo 384, f. 220, 1931.
} 
Posterior a este primer conflicto, aparece otro con colonos, pero ya esta vez Carlos Fidel Cano es propietario de la finca Salinas, según las fuentes este conflicto se da entre 1936 y 1938. Los colonos implicados en el pleito eran Efraím Hincapié, Efrén Rodríguez y Claudia García, quienes poseían mejoras en la finca de Cano. El gamonal, para poder expulsar a los campesinos presentó querellas frente a la Alcaldía e incluso el inspector seccional de la Oficina del Trabajo, que cumplió el rol de mediador entre los colonos y Cano, los reunió en la Alcaldía "para oír las reclamaciones de parte y parte y tratar de zanjar definitivamente y con equidad la diferencia". Finalmente, el conflicto es ganado por Cano quien tenía una situación jurídica más ventajosa, ya que poseía

\begin{abstract}
"copia de un instrumento público indicativo de que [...] adquirió el lote de terreno que ocupan los trabajadores por compra hecha a los herederos del extinto Gonzalo Pérez en el año de 1895 [...] No aparece comprobado que el primitivo poseedor haya adquirido a título de compra o de adjudicación aquellos terrenos y esta puede ser una deficiencia en los títulos del señor Cano pero nunca capaz de colocarlo en posición desventajosa respecto a los trabajadores". ${ }^{14}$
\end{abstract}

Si bien, los títulos que fueron presentados por Cano podían ser cuestionados, como ocurría en repetidas ocasiones, cuando había controversias entre colonos y gamonales, el juez de tierras resolvió lanzar a Efraím Hincapié, multarlo y, finalmente, darle 200 días de cárcel, los cuales fueron reducidos a 30 porque el colono realizó trabajos de obras públicas. En este caso, a diferencia del de Cisneros, se observa una apropiación mayor de la legislación, Cano, a diferencia de Rafael Castaño, no hizo un uso tan sistemático de la violencia; es más intentó evitar las acciones de hecho, por medio de la interposición de querellas y la presencia de agentes de policía en sus predios. La única acción violenta que registraron los colonos fue la destrucción de los cercos que habían construido en sus mejoras.

Ahora bien, en su papel de intermediario apareció en 1936, cuando abogó para que el alcalde de turno, Horacio Valencia (liberal), no fuera removido del cargo. Ahora, Cano aparece firmando memoriales al lado de los vecinos notables de Yolombó e incluso es calificado por el alcalde Valencia así: “Don Carlos Fidel Cano y Don Pedro Luis Gómez son las personas más honorables de la población y con ellos está el pueblo sensato que apoya

\footnotetext{
${ }^{14}$ AHA. Secretaría de Gobierno. Gobierno Municipios, Yolombó, Tomo 541, f.451, 1936.
} 
todos mis actos, ya que ellos son los dirigentes". ${ }^{15}$ Es así como Cano se convierte en uno de los voceros a favor del alcalde Valencia.

En este punto, cabe referirnos al contexto más general. Durante la década del treinta, cuando se instala la República Liberal, inició un proceso de modernización que consistió, principalmente, en la centralización y en el fortalecimiento del Estado por medio del incremento de la capacidad fiscal, la secularización y ampliando la ciudadanía, lo cual se realizó a través de la movilización partidaria y las redes clientelares (PALACIOS, 1999, p. 96). En consecuencia, los liberales buscan que quienes ocupaban los cargos administrativos en las regiones nges pusieran en marcha el proyecto político liberal, por ello, buscaron que los gobernadores departamentales se adscribieran a las ideas del partido.

En el caso de Antioquia, el primer gobernador liberal del siglo XX fue Julián Uribe Gaviria (1932-1934), hijo del General Rafael Uribe Uribe y a quien le siguieron otros gobernadores liberales, quienes a su vez designaron alcaldes de ese partido, especialmente en estas zonas de frontera del departamento (Nordeste, Bajo Cauca, Magdalena Medio), caracterizadas por su liberalismo. No obstante, los alcaldes, al ser nombrados por los gobernadores, enfrentaban una serie de dificultades que les impedían permanecer en el cargo por mucho tiempo. En esta época fue constante el cambio de alcaldes en los municipios. Al revisar la correspondencia, que llegaba a la Secretaría de Gobierno departamental, se observa que un importante volumen de esta correspondencia son cartas y memoriales de vecinos, en las que se le solicitaba al Gobernador la remoción de los alcaldes de turno. De acuerdo con la ley el funcionario debía permanecer en el cargo durante al menos un año; sin embargo, los vecinos notables y las autoridades locales, cuando no simpatizaban con estos funcionarios, pedían que fueran cambiados, por tanto, este cargo era efímero, en cambio el gamonal era estable. Por esta razón, los alcaldes (que muchas veces no eran oriundos del municipio) debían ganar el respeto de los otros funcionarios y, particularmente, de los miembros de los concejos municipales (elegidos por voto popular), propiciando un ambiente de concordia entre ambos partidos, ya que los concejales, además de decidir

\footnotetext{
${ }^{15}$ AHA. Secretaría de Gobierno. Gobierno municipios, Yolombó, Tomo 541, f.408, 1936.
} 
sobre las propuestas y proyectos que presentaban los alcaldes, elegían a los funcionarios más importantes de la administración local: el juez, el personero, el tesorero y los agentes de policía. (AGUDELO, 2014)

Fue esta la situación que tuvo que enfrentar Valencia a finales de 1936, cuando algunos vecinos de Yolombó buscaban que fuera removido de su cargo. Aunque, paralelamente, también fue apoyado por varios vecinos notables, entre ellos Cano, quienes consideraban que la destitución del funcionario antes de las elecciones propiciaría conflictos políticos. Carlos Fidel Cano envió una carta al gobernador de Antioquia, Francisco Cardona Santa, para que conservara a Valencia en el puesto, ya que “interpreta la política sana que Ud. defiende y a la cual nos encontramos nosotros estrechamente vinculados [...] La opinión general es de satisfacción por las actuaciones del sr. Valencia”. ${ }^{16}$ La defensa del alcalde enfrentó a algunos vecinos del pueblo, unos que como Carlos Fidel Cano lo defendían y otros que buscaban su remoción, como Luis Eduardo Vanegas Franco, quien representa el segundo caso de gamonalismo en Yolombó que, aquí, se describirá.

Este caso corresponde más al rol del político profesional, adscrito al partido liberal. Luis Eduardo Vanegas era vecino y natural de Yolombó y propietario de la finca Casa Nueva. En Yolombó hay un episodio que cobra relevancia; (es referido en la documentación en reiteradas ocasiones), el triunfo de los liberales en 1937, después de esta fecha el municipio se vuelve, mayoritariamente, liberal. Esto significaba que este partido tendría mayor participación en el Concejo Municipal. En consecuencia, se produjeron disputas entre conservadores y liberales, que desde sus directorios incitaban los ánimos de la población. ${ }^{17}$ En este contexto, aparece la figura de Luis Eduardo Vanegas, quien, desde 1934, es referido en la documentación, primero como secretario del Directorio Liberal del municipio, luego como su presidente, posteriormente como jefe de una de las facciones del liberalismo, la que se oponía al liberalismo de izquierda ${ }^{18} \mathrm{y}$,

\footnotetext{
${ }^{16}$ AHA. Secretaría de Gobierno. Gobierno municipios, Yolombó, Tomo 541, f.429, 1936.

17 Ya para 1945 había 2781 liberales, 34 disidentes y 295 conservadores. Ver: AHA. Secretaría de Gobierno, Gobierno municipios, Yolombó, Tomo 517, Carpeta 3, f. 169, 1945.

${ }^{18}$ Para la época en que Vanegas es reconocido como jefe del liberalismo, se habla de la izquierda liberal. En este caso, si bien no se habla en la documentación explícitamente de Gaitán, se reconoce que para la década del cuarenta el liberalismo de izquierda tiene su expresión en el Gaitanismo, en el excelente trabajo de John Green sobre Gaitanismo y liberalismo de izquierda se explica a profundidad. Además,
} 
gobernador de Antioquia solicitando cambio de alcaldes conservadores e incluso liberales, como en el caso de Horacio Valencia, hasta el punto de ser conocido como el "tumba alcaldes".

En su rol de jefe de facción del liberalismo, Vanegas tiene un papel destacado, especialmente en las elecciones de 1945, cuando tuvo enfrentamientos con Luis Amaya C., vecino de Yalí $^{19}$, representante del liberalismo de izquierda y miembro principal del jurado electoral. Amaya, por medio de una carta al Gobernador de Antioquia, denunciaba que Vanegas tenía a su favor la maquinaria política para ganar las elecciones como diputado. Por ello, solicitaba al gobernador agentes de policía departamentales que permitieran el normal curso de las elecciones; previniendo que ocurriera lo mismo que en 1941, cuando se encarcelaron a varios representantes del liberalismo de izquierda del municipio. Según Amaya, la corriente que él representaba contaba con el apoyo de las mayorías de Yolombó y Yalí, por tanto, la candidatura de Vanegas carecía de legitimidad y se veía forzado a aglutinar a los liberales "que no quieren oírlo" porque "marchan firmes y sin temores al compás de los tambores de la izquierda". En la carta, también, denunciaba la forma en que el liberalismo estaba intentando proyectar su poder, la cual era inconveniente para la estabilidad del partido, puesto que quedaba sometida "a la voluntad absolutista de los caciques de parroquia que, sin sentido responsabilidad y preocupados únicamente en el medro personal se obstinan en sostener posiciones que no son capaces de representar" 20 .

Estas denuncias permiten observar cómo el sistema político colombiano dependía de los gamonales para poner en marcha la maquinaria política en época de elecciones. En la carta que Amaya dirige al Gobernador, advierte que las estrategias para ganar las

estas zonas de frontera en Antioquia fueron, particularmente, receptivas al discurso de Gaitán. Ver: (ROLDAN 2000)

${ }^{19}$ Esta es una característica para resaltar dada las rivalidades entre Yalí, que aspiraba ser un municipio independiente y Yolombó. En la documentación del fondo Gobierno Municipios hay varios memoriales de los vecinos de Yalí, solicitando que el corregimiento se erigiera como municipio, lo cual no se lograría, sino hasta la década del sesenta.

${ }^{20}$ AHA. Secretaría de Gobierno, Gobierno municipios, Yolombó, Tomo 517, Carpeta 3, f. 127, 1945. 
elecciones en 1941 estuvieron auspiciadas por el Gobernador de turno, que prefería como representante de Yolombó a Vanegas. John Green (GREEN, 2013) en su estudio sobre el Gaitanismo y liberalismo de izquierda, nos alerta sobre el significado de la expresión maquinaria política, que en Colombia se usa para referirse a la manipulación del sistema electoral por parte del gamonal. Los liberales de izquierda estaban muy conscientes de la existencia de estas prácticas, con las que no pudieron competir. Además, dicho sea de paso, les generaba indignación, dada la manipulación y el fraude que ejercían los gamonales.

En 1945, el liberalismo “vaneguista” triunfó en Yolombó y a Luis Amaya se le inició un sumario por impedir que se pusiera propaganda política en Yalí. Esta pugna entre líderes no pasó desapercibida por las autoridades departamentales, por lo que un visitador administrativo fue enviado al municipio y concluyó que el liberalismo del municipio estaba efectivamente organizado. Dentro de sus estrategias estaba la instrucción del electorado, por medio del Directorio Liberal y la eficaz cedulación de los campesinos. El funcionario advertía que, en estas estrategias organizativas del electorado, Luis Eduardo Vanegas tenía un papel fundamental. Además, el visitador en su informe deja ver cómo se van construyendo las redes de poder, puesto que, Vanegas entabló relaciones con el clero en época de elecciones, con el fin de cooptar el electorado campesino:

Pudo haber existido cierta forma de coacción, no propiamente sobre el electorado liberal, sino sobre el conservador, por las repetidas arengas que el domingo, día de esas elecciones dirigió desde el pulpito el señor cura párroco aconsejando a sus oyentes que votaran por la lista encabezada por el señor Vanegas Franco y como los campesinos conservadores obedecen ciegamente a su párroco, seguramente algunos de ellos votaron por la única lista que figuró en los escrutinios de la cabecera que fue la liberal encabezada por el Sr. Vanegas. ${ }^{21}$

Es de recordar que el clero ha sido uno de los actores del conflicto político colombiano. La Iglesia en Colombia tuvo un rol fundamental en la organización de la sociedad y estuvo alineada, principalmente, con los núcleos del pensamiento conservador colombiano. No obstante, el clero provinciano se comportaba de manera distinta al

\footnotetext{
${ }^{21}$ AHA. Secretaría de Gobierno. Gobierno municipios, Yolombó, Tomo 524, Carpeta 4, f. 58. 1946.
} 
metropolitano, ya que operaba con mayor autonomía respecto de la estructura jerárquica de la Iglesia. (GUERRERO, 2007) De ahí que en el caso de Yolombó y, en general, de las zonas de frontera, en donde la Iglesia no tuvo el mismo peso que en las zonas centrales, el clero local dirigiera procesos políticos, en este caso, el cura párroco defendió los intereses de un político adscrito al partido liberal, que en estas subregiones era mayoritario.

Lo que es de destacar en Vanegas es su trayectoria política, primero como militante del partido liberal, para convertirse en un importante jefe político, representante de los intereses yolombinos en la Asamblea. Por medio de su trayectoria puede inferirse que participó en procesos de negociación, no solo con el poder regional, sino también con funcionarios locales y con el clero. Además, de observar las disputas entre las facciones del liberalismo y la manera en que los gamonales manipulaban la maquinaria electoral.

Las últimas referencias que fueron encontradas de Carlos Fidel Cano y Luis Eduardo Vanegas son de 1952, cuando, a través de unos testimonios de campesinos, son acusados de apoyar a bandoleros en la zona. Esto coincide con el periodo de mayor intensidad de La Violencia en estas zonas de frontera, justo cuando se empezaron a conformar bandas de guerrilleros liberales, las cuales operaron gracias a las ayudas de algunos jefes políticos locales. ${ }^{22}$ Esta última fase estuvo caracterizada por un bandolerismo de tipo social en las zonas de frontera, que pudo operar, al menos en un primer momento, por medio de las ayudas de algunos hacendados y vecinos notables adscritos al partido liberal y que participaron en las Juntas Revolucionarias, conformadas tras el asesinato de Jorge Eliecer Gaitán. Habría que identificar si este apoyo se tradujo en una estrategia clientelar por parte de estos dos actores, buscando quizá conservar la

\footnotetext{
${ }^{22}$ Sobre el fenómeno del bandolerismo en Colombia, es referencia obligada el libro de Gonzalo Sánchez y Donny Meertens: Bandoleros, gamonales y campesinos. En este trabajo, los autores hacen una clasificación del bandolerismo durante la época de La Violencia en Colombia, caracterizándolo como uno de tipo social y político. Los bandoleros colombianos van a transitar a través de la ruptura con la dominación oligárquica a través del bipartidismo, pasando por su transformación en auténticos revolucionarios hasta llegar al modelo tipo descrito por Eric Hobsbawm, quien caracteriza al bandido social como una especie de Robin Hood que se convierte en el héroe protector de los campesinos perseguidos. No obstante, Sánchez y Meertens no excluyen los bandoleros que tuvieron motivaciones más de tipo económico. En las zonas de frontera del departamento de Antioquia, este tipo de bandolero primó, especialmente, después de la conformación del Frente Nacional.
} 
hegemonía liberal en el municipio. Además, no es de extrañar que cuando los gamonales en Colombia perdían su poder de negociación, recurrían a la violencia para alcanzar sus fines.

\section{A modo de conclusión}

En primer lugar, hay que mencionar las limitaciones para abordar el objeto de estudio, que apuntan, principalmente, a la dificultad de seguir la trayectoria de estos personajes, esta es una tarea desafiante para quienes investigan esta temática, ya que los vestigios que fueron dejados por estos personajes están dispersos; por tanto, requeriría la búsqueda no solo en archivos regionales, sino también locales y nacionales. En este artículo, nos enfocamos principalmente en la zona del Nordeste antioqueño, ya que es la zona en donde mayor número de información pudo encontrarse para intentar ilustrar los casos.

Ahora bien, esta primera clasificación sobre el fenómeno del gamonalismo en el Nordeste esboza los cambios que este actor tiene durante el periodo escogido. El gamonalismo, en esta zona, operó a través de mecanismos de dominación basados en la coacción, sin embargo, estos mecanismos empezaron a ser modificados por otros que no descansaron, exclusivamente, en la manipulación o explotación del campesinado. El caso de Cisneros se asemeja a las formas que adoptó el gamonalismo en Ecuador y Perú, en donde los gamonales fueron fundamentales en la consolidación de grandes haciendas. A su vez, esta ejemplificación muestra las limitaciones de este tipo de gamonal para armar una red de intercambios clientelares, por lo que su esfera de poder queda limitada al mundo de la hacienda. También, el análisis detenido de este sujeto nos permite observar las diferencias, a veces sutiles entre este tipo de gamonal y el empresario agrícola.

El caso de Luis Eduardo Vanegas es, particularmente, ilustrativo en lo que tiene que ver con la faceta del gamonal, que se presenta más como actor eslabón, de manera similar a los jefes políticos mexicanos, estos sujetos tuvieron la capacidad de crear alianzas con los poderes locales y con las autoridades departamentales. Además, tuvieron una labor fundamental en la movilización de las redes partidistas, en tanto una de sus 
funciones fue la de conseguir votos para el partido liberal. Para ello, este actor se valió de distintas estrategias como las alianzas con distintos funcionarios locales y el clero, el fraude electoral. Quedan varias preguntas en torno a este sujeto, que tienen que ver, particularmente, por la forma en que se expresan las relaciones que entabla con el campesinado, no desde la explotación, sino más bien a partir de los mecanismos de intercambio de bienes y servicios. Lo que hace pensar cómo se expresan y cuáles son los elementos de reciprocidad, propios del clientelismo, entre gamonales y sujetos populares. A su vez, la participación de estos sujetos en la época más álgida de la Violencia en la zona nos presenta la violencia como una estrategia fundamental al momento de agotar los intercambios propios de las redes clientelares.

\section{Referencias}

AGUDELO MORALES, Jorge Alberto. La acusación como forma de intimidación política en San Vicente. Historelo: Revista de Historia Regional y local, Medellín, v. 11, n. 6, p. 251-74, enero/junio, 2014. http://www.redalyc.org/articulo.oa?id=345832084008

ANRUP, Ronald. 1990. El taita y el toro. En torno a la configuración patriarcal del régimen hacendario cuzqueño. Estocolmo: Universidad de Gotemburgo. Instituto de Estudios Latinoamericanos, Universidad de Estocolmo, 1990.

BETANCOUT, Dario; GARCÍA, Martha. Matones y cuadrilleros. Origen y evolución de la violencia en el occidente colombiano. 1946-1965. Bogotá: Tercer Mundo Editores, IEPRI, 1990.

CONTRERAS HERNÁNDEZ, Jesús. El gamonalismo local y la reforma agraria: El caso de Chinchero, 1940-1979. Boletín Americanista, España, nº 31, p. 15-39, 1980.

https://dialnet.unirioja.es/servlet/articulo?codigo $=2937908$

GUERRERO, Javier. Los años del olvido. Boyacá y los orígenes de la violencia. Tunja: Universidad Pedagógica y Tecnológica de Colombia, 2007.

IBARRA CRESPO, Hernán. Origen y decadencia del gamonalismo en la sierra ecuatoriana. Anuario de Estudios Americanos, Quito, v. 59, n.2, p. 491-510, 2002. https://doi.org/10.3989/aeamer.2002.v59.i2.183

LEGRAND, Catherine. Colonización y protesta campesina en Colombia. 1850-1950. Bogotá: Universidad Nacional de Colombia, 1988. 
MANRIQUE, Nelson. Expansión terrateniente y Gamonalismo en el sur peruano. Travesía, Buenos Aires, n. 5, p. 249-69, enero/junio, 2001. http://www.travesiaunt.org.ar/pdf/travesia56_8.pdf

ORTIZ SARMIENTO, Carlos Miguel. Estado y subversión en Colombia. La Violencia en Quindío años 50. Bogotá: Fondo Editorial CEREC, CIDER Uniandes, 1985.

ROLDAN, Mary. Genesis and evolution of La Violencia in Antioquia, Colombia (1900-1953). Cambridge, Massachusetts, Department of History, Harvard University, 1992.

ROLDAN, Mary. Limitaciones locales de un movimiento nacional: Gaitán y el gaitanismo en Antioquia. Análisis Político, Bogotá, n`39, p.17-35, enero/abril, 2000.

SCOTT, James. Weapons of the weak: everyday forms of peasant resistance. New Haven: Yale University Press, 1985.

VÁZQUEZ PIÑEROS, María del Rosario. Gamonales y alcaldes : poder institucional y parainstitucional en la Primera Violencia ( Colombia , 1930-1934 ). Revista de Indias, España, v. 77, n. 269, p.305-34, 2017. doi:10.3989/revindias.2017.010 